\title{
A Pilot Study of Chemoradiotherapy With Weekly Docetaxel for Thoracic Esophageal Carcinoma With T4 and/or M1 Lymph Node Metastasis
}

\author{
Isamu Makino, c, Itasu Ninomiya a, Koichi Okamoto ${ }^{a}$, Jun Kinoshita ${ }^{a}$, Hironori Hayashi ${ }^{a}$, Keishi Nakamura \\ Katsunobu Oyama ${ }^{a}$, Hisatoshi Nakagawara ${ }^{a}$, Hideto Fujita ${ }^{a}$, Hidehiro Tajima ${ }^{a}$, Hiroyuki Takamura ${ }^{a}$, \\ Hirohisa Kitagawa ${ }^{a}$, Sachio Fushida ${ }^{a}$, Takashi Tania ${ }^{a}$, Takashi Fujimura, \\ Tetsuo Ohta ${ }^{\mathrm{a}}$, Tsuyoshi Takanaka ${ }^{\mathrm{b}}$
}

\begin{abstract}
Background: Patients with unresectable or inoperable esophageal carcinoma are usually treated with definitive chemoradiotherapy. The present standard regimen is radiation with concurrent chemotherapy with cisplatin and fluorouracil. However, significant toxicities have been observed. The efficacy and safety of concurrent chemoradiotherapy with weekly docetaxel for head-and-neck squamous cell carcinoma and non-small cell lung cancer have already been recognized. We conducted a pilot study of definitive chemoradiotherapy with weekly docetaxel for advanced esophageal carcinoma.
\end{abstract}

Methods: Nine patients with advanced thoracic esophageal squamous cell carcinoma having a T4 tumor and/or distant lymph node metastasis (M1 LYM) were enrolled. Docetaxel was administered concurrently with $60 \mathrm{~Gy}$ of radiation by drip infusion at a dose of 10 $\mathrm{mg} / \mathrm{m}^{2}$ for an hour once per week and 6 times in total.

Results: All 9 patients completed the treatment schedule without any suspension. Grade 3 or higher hematological and biochemical toxicities did not occur. Two patients achieved complete response,

Manuscript accepted for publication October 14, 2011

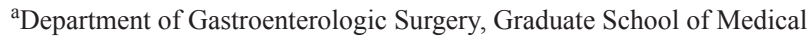
Science, Kanazawa University, 13-1 Takaramachi, Kanazawa, Ishikawa 920-8641, Japan

${ }^{b}$ Department of Radiology, Graduate School of Medical Science,

Kanazawa University, 13-1 Takaramachi, Kanazawa, Ishikawa 920-8641, Japan

${ }^{\mathrm{c} C o r r e s p o n d i n g ~ a u t h o r: ~ I s a m u ~ M a k i n o, ~}$

Email: makino@staff.kanazawa-u.ac.jp

doi:10.4021/wjon $407 \mathrm{w}$ and 4 achieved partial response. The response rate was $67 \%$. The median survival time was 16.2 months and the 2-year survival rate was $38.9 \%$

Conclusions: Concurrent chemoradiotherapy with weekly low dose docetaxel is a safe and effective treatment regimen for esophageal squamous cell carcinoma. We expect that this protocol of chemoradiotherapy may be one of the choices of treatment substituting the regimen with cisplatin and fluorouracil, particularly for the patients for whom chemotherapy with cisplatin and fluorouracil is considered inappropriate because of concomitant renal dysfunction or prior failure of systemic chemotherapy with cisplatin and fluorouracil.

Keywords: Esophageal cancer; Squamous cell carcinoma; Docetaxel; Chemoradiotherapy

\section{Introduction}

Carcinoma of the esophagus is a highly malignant disease and the treatment outcome has been poor. Patients with unresectable or inoperable disease are usually treated with definitive chemoradiotherapy. Based on the results of the Radiation Therapy Oncology Group (RTOG) phase III intergroup trial RTOG 85-01, the present standard regimen is radiation with concurrent chemotherapy with cisplatin and fluorouracil $[1,2]$. In Japan, 2 phase II studies of definitive chemoradiotherapy with cisplatin and fluorouracil for advanced thoracic esophageal squamous cell carcinoma (TESCC) with T4 tumor and/or distant lymph node metastasis (M1 LYM) were performed $[3,4]$. The complete response (CR) rate of each study was $33 \%$ [3] and $15 \%$ [4], and the survival rate was $23 \%$ at 3 years [3], and $31.5 \%$ at 2 years [4], respectively. However, significant toxicities, particularly severe hematological toxicities associated with these treatment regimens, have been observed [3, 4].

The efficacy and safety of concurrent chemoradiotherapy with weekly docetaxel for head-and-neck squamous cell carcinoma (HNSCC) [5-8] and non-small cell lung cancer (NSCLC) [9-12] have already been recognized. According to Japanese reports [7], the recommended dose of docetaxel 


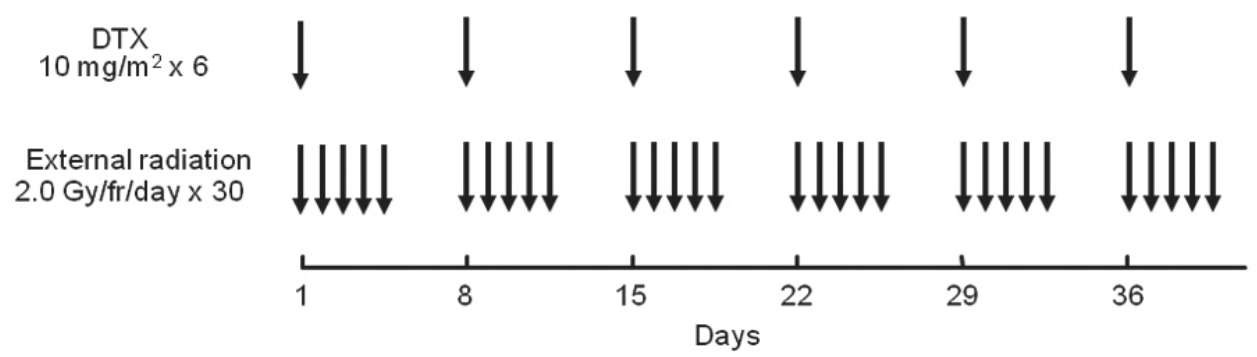

Figure 1. Treatment schedule of chemoradiotherapy with weekly docetaxel. DTX: docetaxel.

in the concurrent chemoradiotherapy for HNSCC was weekly administration of $10 \mathrm{mg} / \mathrm{m}^{2}$.

We conducted a pilot study of concurrent chemoradiotherapy with weekly docetaxel for TESCC with T4 and/or M1 LYM. We administered docetaxel according to the protocol described in Japanese reports of HNSCC [7]. Herein, we report the efficacy and safety of this regimen.

\section{Patients and Methods}

\section{Patients}

From October 2005 to March 2009, 9 patients with advanced TESCC having a T4 tumor and/or M1 LYM were enrolled in this study. The criteria for inclusion in this study were

Table 1. Patient characteristics

\begin{tabular}{lr}
\hline Characteristic & $\mathbf{n}=\mathbf{9}$ \\
\hline Age (years) & 66 \\
Median & $51-78$ \\
Range & \\
Gender & 1 \\
Female & 8 \\
Male & \\
Performance status & 7 \\
0 & 2 \\
1 UICC TNM stage & \\
non-T4 M1 LYM & \\
T4 M0 & 4 \\
T4 M1 LYM & 4 \\
Primary tumor site & 1 \\
Upper thoracic esophagus & \\
Middle thoracic esophagus & \\
Lower thoracic esophagus & \\
Cervical node & \\
\hline
\end{tabular}


Table 2. Summary of toxicity

\begin{tabular}{|c|c|c|c|c|c|c|}
\hline & \multicolumn{5}{|c|}{ Grade $(n=9)$} & \multirow[b]{2}{*}{$\% \geq \geq$ Grade 3} \\
\hline & $\mathbf{0}$ & 1 & 2 & 3 & 4 & \\
\hline \multicolumn{7}{|l|}{ Acute toxicity } \\
\hline \multicolumn{7}{|l|}{ Hematological } \\
\hline Leukopenia & 8 & 0 & 1 & 0 & 0 & 0 \\
\hline Neutropenia & 8 & 0 & 1 & 0 & 0 & 0 \\
\hline Anemia & 4 & 3 & 1 & 0 & 0 & 0 \\
\hline Thrombocytopenia & 8 & 0 & 1 & 0 & 0 & 0 \\
\hline \multicolumn{7}{|l|}{ Biochemical } \\
\hline Bilirubin & 9 & 0 & 0 & 0 & 0 & 0 \\
\hline AST & 7 & 2 & 0 & 0 & 0 & 0 \\
\hline ALT & 7 & 2 & 0 & 0 & 0 & 0 \\
\hline Creatinine & 8 & 1 & 0 & 0 & 0 & 0 \\
\hline \multicolumn{7}{|l|}{ Non-hematological } \\
\hline Anorexia & 6 & 1 & 0 & 2 & 0 & 22 \\
\hline Nausea & 9 & 0 & 0 & 0 & 0 & 0 \\
\hline Vomiting & 8 & 0 & 1 & 0 & 0 & 0 \\
\hline Esophagitis & 6 & 1 & 0 & 2 & 0 & 22 \\
\hline Esophageal bleeding & 7 & 0 & 1 & 1 & 0 & 11 \\
\hline Dermatitis & 7 & 1 & 1 & 0 & 0 & 0 \\
\hline \multicolumn{7}{|l|}{ Late toxicity } \\
\hline Peumonitis & 9 & 0 & 0 & 0 & 0 & 0 \\
\hline Pleural effusion & 8 & 0 & 0 & 1 & 0 & 11 \\
\hline Pericardial effusion & 9 & 0 & 0 & 0 & 0 & 0 \\
\hline
\end{tabular}

as follows: newly diagnosed and pathologically confirmed squamous cell carcinoma of the thoracic esophagus; T4 tumor and/or M1 LYM according to the TNM classification of the UICC International Union Against Cancer, $6^{\text {th }}$ edition; no evidence of esophagotracheal or esophagobronchial fistula and distant organ metastasis; performance status (PS) of 0-2 based on the classification criteria of the Eastern Cooperative Oncology Group; age 20-80 years; adequate bone marrow [white blood cell (WBC) count $\geq 3,000 / \mu 1$, neutrocyte count $\geq 1,500 / \mu 1$, hemoglobin $(\mathrm{Hb})$ level $\geq 10.0 \mathrm{~g} / \mathrm{dl}$, platelet count $\geq 100,000 / \mu \mathrm{l}]$, hepatic (total bilirubin $<1.5 \mathrm{mg} / \mathrm{dl}$, alanine transaminase (ALT), aspartate transaminase (AST) $<3.0 \times$ normal limit), pulmonary (PO2 $\geq 60 \mathrm{mmHg}$ ), and renal (serum creatinine $<2.0 \mathrm{mg} / \mathrm{dl}$, creatinine clearance $\geq 50 \mathrm{ml} /$ $\min$ ) functions. Patients with other active synchronous carcinoma, concurrent uncontrolled medical illness, and prior chemotherapy and radiotherapy for any neoplasm were excluded. All patients provided written informed consent before enrollment in this study.

\section{Treatment schedule}

The treatment schedule is summarized in Fig. 1. Docetaxel was administered concurrently with radiotherapy by drip infusion at a dose of $10 \mathrm{mg} / \mathrm{m}^{2}$ for an hour once per week and 6 times in total. Radiation was administered via $10 \mathrm{MV}$ $\mathrm{X}$-ray (1 fraction per day and 5 fractions per week). When the tumor was located in the upper or middle third of the thoracic esophagus, the treatment volume included bilateral supraclavicular lymph nodes as well as the mediastinum in a T-shaped pattern. When the tumor was located in the lower third of the esophagus, the mediastinum and celiac axis 
Table 3. Treatment response and prognosis of 9 patients

\begin{tabular}{|c|c|c|c|c|c|c|c|c|c|}
\hline $\begin{array}{l}\text { Case } \\
\text { No. }\end{array}$ & Age & Gender & $\begin{array}{l}\text { UICC } \\
\text { TNM }\end{array}$ & & $\begin{array}{l}\text { Tumor } \\
\text { site }\end{array}$ & $\begin{array}{l}\text { Tumor size } \\
\text { (cm) }\end{array}$ & $\begin{array}{l}\text { Overall } \\
\text { response }\end{array}$ & $\begin{array}{l}\text { Primary } \\
\text { response }\end{array}$ & Prognosis \\
\hline 1 & 54 & M & $\mathrm{T} 4 \mathrm{MO}$ & & Middle & 8 & $\mathrm{PD}$ & $\mathrm{PD}$ & $8 \mathrm{M}$ died of disease \\
\hline 2 & 78 & M & $\mathrm{T} 4 \mathrm{M} 0$ & & Upper & 12 & $\mathrm{CR}$ & $\mathrm{CR}$ & $\begin{array}{l}27 \mathrm{M} \text { died of esophageal } \\
\text { perforation }\end{array}$ \\
\hline 3 & 60 & M & $\mathrm{T} 4 \mathrm{M} 0$ & & Middle & 15 & $\mathrm{PD}$ & $\mathrm{PD}$ & $2 \mathrm{M}$ died of disease \\
\hline 4 & 51 & M & $\begin{array}{l}\text { T1 } \\
\text { LYM }\end{array}$ & M1 & Lower & 5 & $\mathrm{PD}$ & $\mathrm{CR}$ & $\begin{array}{l}36 \mathrm{M} \text { alive with disease } \\
\text { progression }\end{array}$ \\
\hline 5 & 66 & M & $\begin{array}{l}\text { T1 } \\
\text { LYM }\end{array}$ & M1 & Middle & 3 & PR & $\mathrm{CR}$ & $29 \mathrm{M}$ died of disease \\
\hline 6 & 66 & $\mathrm{~F}$ & $\begin{array}{l}\text { T3 } \\
\text { LYM }\end{array}$ & M1 & Middle & 12 & $\mathrm{CR}$ & $\mathrm{CR}$ & $16 \mathrm{M}$ died of disease \\
\hline 7 & 70 & M & $\begin{array}{l}\text { T3 } \\
\text { LYM }\end{array}$ & M1 & Middle & 10 & PR & $\mathrm{IR} / \mathrm{SD}$ & $\begin{array}{l}5 \mathrm{M} \text { alive with disease } \\
\text { progression }\end{array}$ \\
\hline 8 & 58 & M & $\begin{array}{l}\text { T4 } \\
\text { LYM }\end{array}$ & M1 & Upper & 6 & PR & $\mathrm{IR} / \mathrm{SD}$ & $9 \mathrm{M}$ died of disease \\
\hline 9 & 70 & M & $\mathrm{T} 4 \mathrm{MO}$ & & Upper & 13 & PR & $\mathrm{IR} / \mathrm{SD}$ & $4 \mathrm{M}$ died of disease \\
\hline
\end{tabular}

PD, progressive disease; CR, complete response; PR, partial response; IR, incomplete response; SD, stable disease.

lymph nodes were irradiated and the supraclavicular lymph nodes were excluded if the cervical nodes tested negative. Oblique fields were used to spare the spinal cord after 40 Gy of radiation was delivered by antero-posterior opposed pair portals. Weekly administration of docetaxel was skipped when the WBC, neutrocyte, or platelet count decreased to < $3,000 / \mu 1,<1,500 / \mu 1$, or $<75,000 / \mu 1$, respectively. Radiotherapy was suspended when the WBC, neutrocyte, or platelet count decreased to $<1,000 / \mu 1,<500 / \mu 1$, or $<50,000 / \mu 1$, and was resumed when the counts recovered to $\geq 1,000 / \mu 1$, $\geq 500 / \mu 1$, and $\geq 50,000 / \mu 1$, respectively.

\section{Evaluation of toxicity and response}

Adverse reactions were evaluated according to the National Cancer Institute's Common Terminology Criteria for Adverse Events (NCI-CTCAE), version 4.0. The tumor response associated with the treatment was evaluated according to the Response Evaluation Criteria in Solid Tumors (RECIST) [13]. The response in primary tumors, which were considered as non-target lesions, was examined by endoscopy and evaluated according to the Response Evaluation Criteria for Primary Lesion using Endoscopy defined in the Japanese Classification of Esophageal Cancer published by the Japanese Esophageal Society [14].

\section{Statistical analysis}

Overall survival time was defined as the time from initiation of the treatment to the date of death or date of final follow-up examination. Survival rates were estimated by the KaplanMeier method. All statistical calculations were carried out using SPSS software version 11 (SPSS Inc; Chicago, IL).

\section{Results}

\section{Patient characteristics}

Between October 2005 and March 2009, 9 patients were enrolled in this study. The characteristics of these 9 patients are listed in Table 1. The median age was 66 years (range, 51 to 78 years). There were 4 patients with non-T4 M1 LYM, 4 patients with T4 M0, and 1 patient with T4 M1 LYM. Four patients had a T4 tumor that invaded into the tracheobronchial tree and 1 patient had a T4 tumor that invaded into both the tracheobronchial tree and thoracic aorta. Among the 5 patients with M1 LYM, 4 patients had cervical lymph node metastases, and 1 patient had both cervical and abdominal lymph node metastases.

\section{Toxicity}

All patients completed treatment with a total radiation dose of 60 Gy without any suspension. The most severe toxicities during the treatment and follow-up period are summarized in Table 2. Grade 3 or higher hematological and biochemical toxicities did not occur. The most frequent toxicities were anorexia and esophagitis. A patient with T4 disease developed treatment-related perforation of the esophageal wall 
Table 4. Summary of response and survival

\begin{tabular}{ll}
\hline Number of patients & $\mathbf{9}$ \\
\hline Response rate & $67 \%(\mathrm{CR} \mathrm{22 \% ;} \mathrm{PR} \mathrm{44 \% )}$ \\
Median survival time & 16.2 months (95\% CI: 4.9-27.5) \\
2-year survival rate & $38.9 \%$ \\
\hline
\end{tabular}

$\mathrm{CR}$, complete response; $\mathrm{PR}$, partial response; $\mathrm{Cl}$, confidence interval.

and died because of esophago-mediastinal fistula 27 months after initiation of the treatment. There was $1(11 \%)$ death related to the treatment.

\section{Response}

Individual data of the treatment response and prognosis are listed in Table 3. Of the 9 patients, 2 (22\%) achieved CR, and $4(44 \%)$ achieved PR. The response rate was $67 \%$ (Table $4)$. The other 3 patients (33\%) had progressive disease (PD). $\mathrm{PD}$ in these 3 patients developed because of progression of the primary lesion, development of lung metastases, and development of bone metastases, respectively. As far as the response of primary tumors were concerned, 4 patients (44\%), including one with T4 disease, achieved CR.

\section{Survival}

The prognoses of the 9 patients are listed in Table 3, and the overall survival curves are shown in Fig. 2. The median survival time (MST) was 16.2 months (95\% confidence inter- val: 4.9-27.5 months) and the 2-year survival rate was $38.9 \%$ (Table 4).

\section{Discussion}

The present standard regimen of chemoradiotherapy for TESCC is radiation and concurrent chemotherapy with cisplatin and fluorouracil [1-4]. However, because other treatment regimens have not been established, there is no recommended choice of treatment for patients for whom chemotherapy with cisplatin and fluorouracil is considered inappropriate because of concomitant renal dysfunction or prior failure of systemic chemotherapy with cisplatin and fluorouracil. Moreover, significant toxicities, particularly severe hematological toxicities, associated with this treatment regimen, have been observed [1-4]. Other effective and reliable chemoradiotherapy regimens in addition to the one with cisplatin and fluorouracil are needed.

The concurrent use of taxanes (docetaxel and paclitaxel) with radiation has been employed for the treatment of pa-

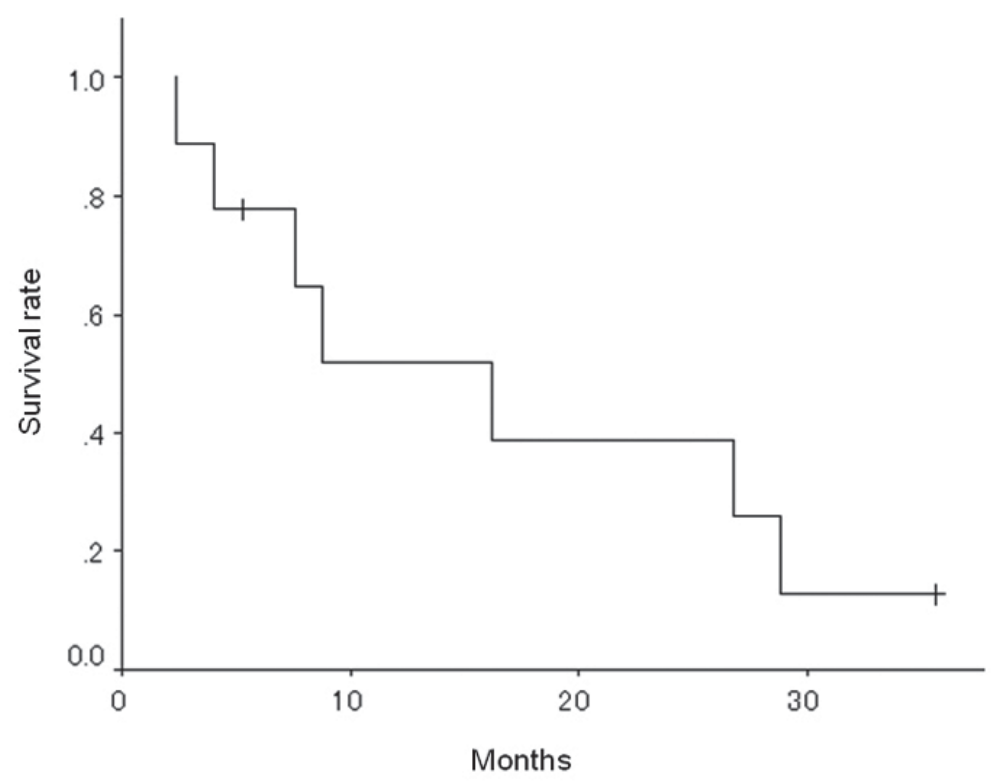

Figure 2. Overall survival of 9 patients. 
tients with HNSCC [5-8] and NSCLC [9-12]. Many clinical and experimental studies have demonstrated the efficacy of concomitant administration of taxanes with radiation [1522]. The efficacy of taxanes is based on not only their cytotoxicity but also their radio-sensitizing effect. Microtubule modification initiated by taxanes causes cells to accumulate in the radio-sensitive G2/M phase of the cell cycle. The radio-sensitizing effect of taxanes is thought to be derived mainly from this mechanism. Furthermore, in vitro and in vivo studies have demonstrated roles for the p53 pathways and apoptotic mechanism as contributing factors of the therapeutic benefits of combining taxanes with concurrent radiation.

Taxanes are usually administered every 3 weeks as a single cytotoxic agent; however, there are several reports showing that weekly administration of taxanes may be the most effective dosing regimen in combination with radiation $[12,23]$. Most of regimens of docetaxel with concurrent radiotherapy consist of weekly administration of docetaxel at a dose of $10-30 \mathrm{mg} / \mathrm{m}^{2}$ [5-12]. The most appropriate dosage of docetaxel may be different among the types of tumor, range of irradiation fields, and ethnic origin of the patients. In this pilot study, we administered docetaxel according to the protocol described in Japanese reports of HNSCC [7], considering the racial identity and oncological similarity between TESCC and HNSCC.

In the present study, the overall $\mathrm{CR}$ and response rate were $22 \%$ and $67 \%$, respectively. The median survival time was 16.2 months and the 2-year survival rate was $38.9 \%$. These results are compatible to those in previous Japanese reports of concurrent chemoradiotherapy with cisplatin and fluorouracil for TESCC with T4 and/or M1 LYM [3, 4]. However, grade 3 or higher hematological toxicities did not occur in the present study, although these complications occurred in approximately $20 \%-30 \%$ of patients in the previous Japanese reports [3, 4]. In our study, all 9 patients completed the treatment schedule without any suspension. A critical adverse event occurred in 1 of the 9 patients (11\%), who developed perforation of the esophageal wall and died because of esophago-mediastinal fistula. Although the present study has a limited number of patients, concurrent chemoradiotherapy with weekly low dose docetaxel might be a feasible and promising treatment regimen for TESCC.

We expect that this protocol of chemoradiotherapy may be one of the choices of treatment for TESCC, particularly for the patients for whom chemotherapy with cisplatin and fluorouracil is considered inappropriate because of concomitant renal dysfunction or prior failure of systemic chemotherapy with cisplatin and fluorouracil. Moreover, as one of the treatment options, we plan to combine this regimen with prior induction chemotherapy with cisplatin and fluorouracil to achieve a survival benefit for the patients with advanced TESCC. We are currently conducting a phase I/II study of chemoradiotherapy with docetaxel following induction che- motherapy with cisplatin and fluorouracil in order to determine the appropriate dosage for the weekly administration of docetaxel.

\section{References}

1. Cooper JS, Guo MD, Herskovic A, Macdonald JS, Martenson JA, Jr., Al-Sarraf M, Byhardt R, et al. Chemoradiotherapy of locally advanced esophageal cancer: longterm follow-up of a prospective randomized trial (RTOG 85-01). Radiation Therapy Oncology Group. JAMA. 1999;281(17):1623-1627.

2. Minsky BD, Pajak TF, Ginsberg RJ, Pisansky TM, Martenson J, Komaki R, Okawara G, et al. INT 0123 (Radiation Therapy Oncology Group 94-05) phase III trial of combined-modality therapy for esophageal cancer: high-dose versus standard-dose radiation therapy. J Clin Oncol. 2002;20(5):1167-1174.

3. Ohtsu A, Boku N, Muro K, Chin K, Muto M, Yoshida S, Satake M, et al. Definitive chemoradiotherapy for T4 and/or M1 lymph node squamous cell carcinoma of the esophagus. J Clin Oncol. 1999;17(9):2915-2921.

4. Ishida K, Ando N, Yamamoto S, Ide H, Shinoda M. Phase II study of cisplatin and 5-fluorouracil with concurrent radiotherapy in advanced squamous cell carcinoma of the esophagus: a Japan Esophageal Oncology Group (JEOG)/Japan Clinical Oncology Group trial (JCOG9516). Jpn J Clin Oncol. 2004;34(10):615-619.

5. Tishler RB, Norris CM, Jr., Colevas AD, Lamb CC, Karp D, Busse PM, Nixon A, et al. A Phase I/II trial of concurrent docetaxel and radiation after induction chemotherapy in patients with poor prognosis squamous cell carcinoma of the head and neck. Cancer. 2002;95(7):1472-1481.

6. Tishler RB, Posner MR, Norris CM, Jr., Mahadevan A, Sullivan C, Goguen L, Wirth LJ, et al. Concurrent weekly docetaxel and concomitant boost radiation therapy in the treatment of locally advanced squamous cell cancer of the head and neck. Int J Radiat Oncol Biol Phys. 2006;65(4):1036-1044.

7. Fujii M, Tsukuda M, Satake B, Kubota A, Kida A, Kohno N, Okami K, et al. Phase I/II trial of weekly docetaxel and concomitant radiotherapy for squamous cell carcinoma of the head and neck. Int J Clin Oncol. 2004;9(2):107-112.

8. Fukada J, Shigematsu N, Takeda A, Ohashi T, Tomita T, Shiotani A, Kunieda E, et al. Weekly low-dose docetaxel-based chemoradiotherapy for locally advanced oropharyngeal or hypopharyngeal carcinoma: a retrospective, single-institution study. Int J Radiat Oncol Biol Phys. 2010;76(2):417-424.

9. Hainsworth JD, Vokes EE. Docetaxel (Taxotere) in combination with radiation therapy and the potential 
of weekly administration in elderly and/or poor performance status patients with advanced non-small cell lung cancer. Semin Oncol. 2001;28(1 Suppl 2):22-27.

10. Onishi H, Kuriyama K, Yamaguchi M, Komiyama T, Tanaka S, Araki T, Nishikawa K, et al. Concurrent twodimensional radiotherapy and weekly docetaxel in the treatment of stage III non-small cell lung cancer: a good local response but no good survival due to radiation pneumonitis. Lung Cancer. 2003;40(1):79-84.

11. Brunsvig PF, Hatlevoll R, Berg R, Lauvvang G, Owre K, Wang M, Aamdal S. Weekly docetaxel with concurrent radiotherapy in locally advanced non-small cell lung cancer: a phase I/II study with 5 years' follow-up. Lung Cancer. 2005;50(1):97-105.

12. Brunsvig PF, Andersen A, Aamdal S, Kristensen V, Olsen H. Pharmacokinetic analysis of two different docetaxel dose levels in patients with non-small cell lung cancer treated with docetaxel as monotherapy or with concurrent radiotherapy. BMC Cancer. 2007;7:197.

13. Japan Esophageal Society. Japanese classification of esophageal cancer 10th edition. Kanehara, Tokyo.

14. Therasse P, Arbuck SG, Eisenhauer EA, Wanders J, Kaplan RS, Rubinstein L, Verweij J, et al. New guidelines to evaluate the response to treatment in solid tumors. European Organization for Research and Treatment of Cancer, National Cancer Institute of the United States, National Cancer Institute of Canada. J Natl Cancer Inst. 2000;92(3):205-216.

15. Ringel I, Horwitz SB. Studies with RP 56976 (taxotere): a semisynthetic analogue of taxol. J Natl Cancer Inst. 1991;83(4):288-291.

16. Gueritte-Voegelein F, Guenard D, Lavelle F, Le Goff MT, Mangatal L, Potier P. Relationships between the structure of taxol analogues and their antimitotic activity. J Med Chem. 1991;34(3):992-998.

17. Tishler RB, Geard CR, Hall EJ, Schiff PB. Taxol sensitizes human astrocytoma cells to radiation. Cancer Res. 1992;52(12):3495-3497.

18. Tishler RB, Schiff PB, Geard CR, Hall EJ. Taxol: a novel radiation sensitizer. Int J Radiat Oncol Biol Phys. 1992;22(3):613-617.

19. Choy H, Rodriguez FF, Koester S, Hilsenbeck S, Von Hoff DD. Investigation of taxol as a potential radiation sensitizer. Cancer. 1993;71(11):3774-3778.

20. Wahl AF, Donaldson KL, Fairchild C, Lee FY, Foster SA, Demers GW, Galloway DA. Loss of normal p53 function confers sensitization to Taxol by increasing G2/M arrest and apoptosis. Nat Med. 1996;2(1):72-79.

21. Hennequin C, Giocanti N, Favaudon V. Interaction of ionizing radiation with paclitaxel (Taxol) and docetaxel (Taxotere) in HeLa and SQ20B cells. Cancer Res. 1996;56(8):1842-1850.

22. Milas L, Milas MM, Mason KA. Combination of taxanes with radiation: preclinical studies. Semin Radiat Oncol. 1999;9(2 Suppl 1):12-26.

23. Hainsworth JD, Burris HA, 3rd, Greco FA. Weekly administration of docetaxel (Taxotere): summary of clinical data. Semin Oncol. 1999;26(3 Suppl 10):19-24. 